\title{
Circular Photoinduced Electron Transfer in a Donor-Acceptor- Acceptor Triad
}

\author{
Christopher B. Larsen ${ }^{\star[a]}$ and Oliver S. Wenger ${ }^{*[a]}$
}

\begin{abstract}
Herein is communicated an electron donor-acceptoracceptor $\left(D-A_{1}-A_{2}\right)$ triad that provides the first proof-of-concept for a photoinitiated molecular circuit. Upon photoexcitation into an optical charge-transfer transition between $D$ and $A_{1}$, subsequent thermal electron-transfer from $A_{1}{ }^{-}$to $A_{2}$ is followed by geometric rearrangement in the $D^{+}-A_{1}-A_{2}{ }^{-}$charge-separated state to form an ionpair contact. This facilitates 'forward' charge-recombination between $\mathrm{A}_{2}{ }^{-}$and $\mathrm{D}^{+}$that completes the molecular circuit, with an estimated quantum efficiency of $4 \%$ in toluene at $298 \mathrm{~K}$.
\end{abstract}

The concepts of fully-integrated molecular circuitry and singlemolecule circuitry have long been considered the ultimate goal in the field of molecular electronics. ${ }^{[1]}$ Despite significant attention having been paid to molecules that act as individual circuitry components, such as wires, switches and rectifiers, ${ }^{[2]}$ there have been to date no reports of single molecules that can act as a molecular circuit.

Photoinduced electron transfer (ET) across donor-bridgeacceptor (D-B-A) compounds in solution has been widely investigated as a proxy for one-dimensional molecular wires and to gain deeper insight into ET mechanisms. ${ }^{[3]}$ Often, the goal was to achieve long-lived electron-hole pairs for temporary energy storage, and to decelerate thermal charge recombination (CR) events as much as possible. ${ }^{[4]}$ Common strategies to achieve this include the use of rigid rod-like backbones that help maximizing the donor-acceptor distance and the use of multiple donors or acceptors that permit establishment of a redox gradient. ${ }^{[5]}$

Our approach is conceptually different since we aimed at circular electron transfer rather than long-lived electron-hole pairs. With this specific goal in mind, we synthesized and explored a molecular $\left(\mathrm{D}-\mathrm{A}_{1}-\mathrm{A}_{2}\right)$ triad, comprised of a triarylamine (TAA) donor (D), a primary benzothiadiazole (BTD) acceptor $\left(A_{1}\right)$, and a secondary anthraquinone $(A Q)$ acceptor $\left(A_{2}\right)$, linked together by thiophene (th) bridges (Scheme 1). The TAA-th-BTD-th-AQ compound can conformationally rearrange in the chargeseparated $(C S)$ state to form an ion-pair contact between $\mathrm{TAA}^{\cdot+}$ $\left(D^{*+}\right)$ and $A Q^{--}\left(A_{2}{ }^{-*}\right)$, creating a pseudo-macrocyclic structure that facilitates a pathway for forward (circuit-like) $C R$, such that three sequential unidirectional ET steps can occur within the circuit (left part of Scheme 1). While there have been prior studies of electron delocalization in conjugated macrocycles and 'nanorings', ${ }^{[6]}$ to our knowledge there exists currently no method to control the directionality of the movement of the charge in them, and thus our $D-A_{1}-A_{2}$ triad provides an important proof-of-concept. The

[a] Dr. C. B. Larsen, Prof. Dr. O. S. Wenger

Department of Chemistry

University of Basel

St Johanns-Ring 19, CH-4056 Basel, Switzerland

E-mail: christopherbryan.larsen@unibas.ch oliver.wenger@unibas.ch

Supporting information for this article is given via a link at the end of the document. formation of the ion-pair contact in the CS state is facilitated by the ortho substitution pattern around the central BTD acceptor $\left(\mathrm{A}_{1}\right)$ and the conformational flexibility of the bridging th groups, allowing the Coulombic attraction between $\mathrm{TAA}^{\cdot+}\left(\mathrm{D}^{\circ+}\right)$ and $A Q^{*}$ $\left(A_{2}{ }^{*}\right)$ to bring them into close proximity.

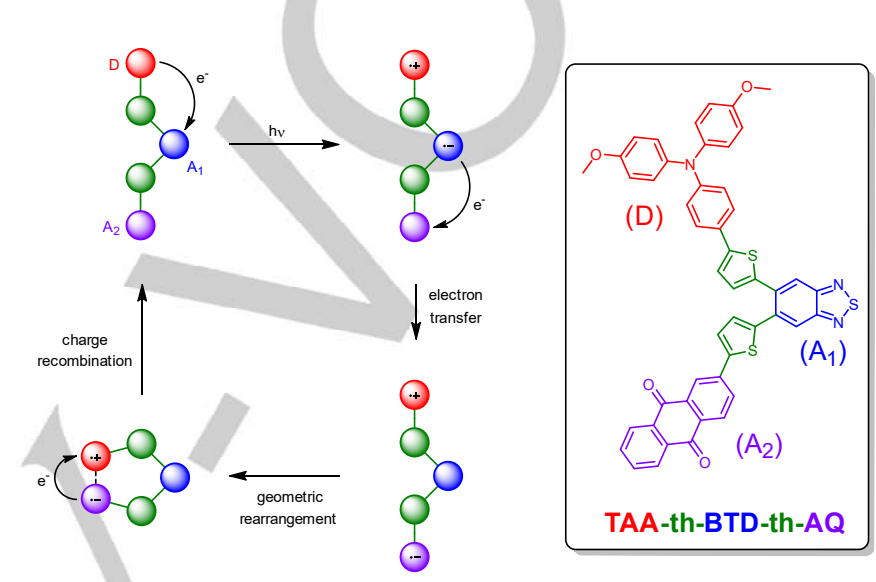

Scheme 1. Proposed mechanism for the charge-transfer processes in the targe $D-A_{1}-A_{2}$ triad. The overall result is circular photoinduced electron transfer. Red $=\mathrm{TAA}$, blue $=\mathrm{BTD}$, purple $=\mathrm{AQ}$, green $=$ th .

Synthesis and characterisation data are presented in the supporting information (SI) on pages S2-S6.

Electronic absorption and photoluminescence spectra of TAA-thBTD-th-AQ and two control compounds, TAA-th-BTD and TAAth-BTD-th-TAA (see Figure $\mathrm{S} 1$ for their complete molecular structures), recorded in $\mathrm{CH}_{2} \mathrm{Cl}_{2}$ are presented in Figure 1. TAAth-BTD, in which the TAA donor and BTD acceptor are free to adopt a coplanar arrangement, exhibits an intense low energy TAA $\rightarrow$ BTD CT band at $447 \mathrm{~nm}$ (black trace, $\varepsilon=22,300 \mathrm{M}^{-1} \mathrm{~cm}^{-1}$ ), consistent with previously reported D-A systems. ${ }^{[7]}$ The second lowest band ( $351 \mathrm{~nm}, \varepsilon=25,800 \mathrm{M}^{-1} \mathrm{~cm}^{-1}$ ) appears consistent with a th $\rightarrow$ BTD CT transition. In the symmetrical TAA-th-BTD-thTAA reference compound, the ortho substitution pattern around the central BTD acceptor sterically inhibits adoption of a coplanar arrangement, and consequently the TAA $\rightarrow B T D C T$ band is hypsochromically shifted to ca. $415 \mathrm{~nm}$ (green trace) such that it becomes merely visible as a shoulder to the higher energy th $\rightarrow$ BTD CT band (355 $\mathrm{nm})$.

The key compound TAA-th-BTD-th-AQ (blue trace in Figure 1) has the lowest energy optical transition occur at essentially the same energy and intensity as for TAA-th-BTD-th-TAA, implying that the lowest energy transition is still TAA $\rightarrow B T D C T$ in nature (solid blue arrow no. 1 in Figure 1). Whilst the higher energy transitions present in TAA-th-BTD-th-TAA also appear to be retained in TAA-th-BTD-th-AQ, it is evident that there are also new transitions. Specifically, we note the presence of a low energy shoulder on the $349 \mathrm{~nm}$ band that we assign to th $\rightarrow A Q$ 
CT (solid blue arrow no. 2) based on electrochemical data (Table $\mathrm{S} 1$ ), as well as TD-DFT calculations (Table S6).

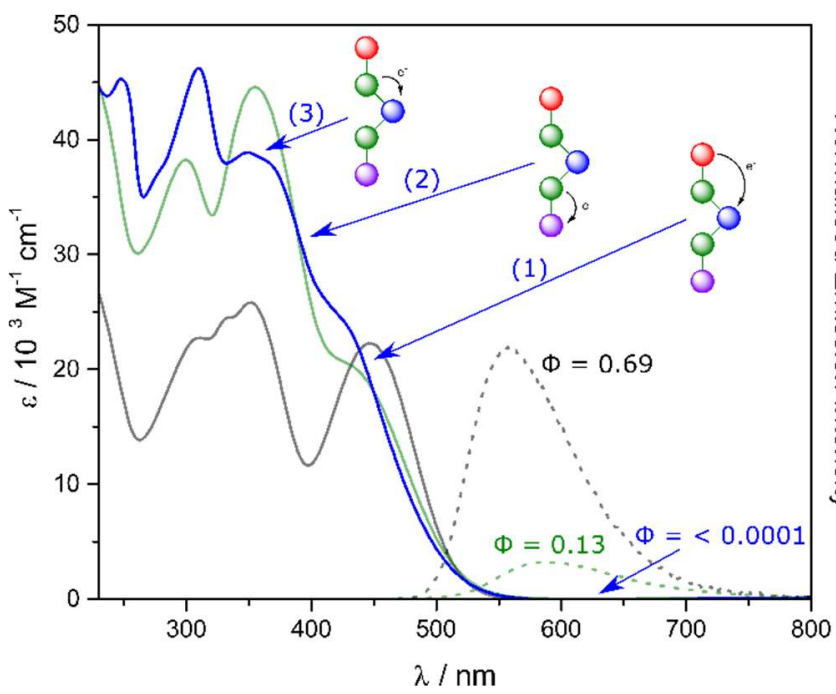

Figure 1. Electronic absorption (solid lines, recorded in $\mathrm{CH}_{2} \mathrm{Cl}_{2}$ ) and photoluminescence spectra (dashed lines, $\lambda_{\mathrm{ex}}=450 \mathrm{~nm}$, recorded in toluene) of TAA-th-BTD (black), TAA-th-BTD-th-TAA (green) and TAA-th-BTD-th-AQ (blue). Schematics depict the nature of optical transitions for TAA-th-BTD-thAQ.

The control compounds, TAA-th-BTD and TAA-th-BTD-th-TAA both exhibit ${ }^{1} \mathrm{CT}$ emission (black and green dotted traces in Figure $1)$, with $\lambda_{\mathrm{em}}$ of $557 \mathrm{~nm}\left(\phi_{\mathrm{PL}}=0.69, \tau=4.0 \mathrm{~ns}\right)$ and $585 \mathrm{~nm}\left(\phi_{\mathrm{PL}}=\right.$ $0.13, \tau=1.7 \mathrm{~ns}$ ), respectively, in toluene (see SI pages S15-S16 for details). The shift to longer wavelengths is consistent with the narrowing electrochemical gap between the TAA oxidation and BTD reduction going from TAA-th-BTD to TAA-th-BTD-th-TAA (Table S1), and is therefore assigned as ${ }^{1}$ TAA $^{*+}$-th-BTD“-th-TAA in nature.

The TAA-th-BTD-th-AQ key compound exhibits only extremely weak emission at $585 \mathrm{~nm}\left(\varphi_{\mathrm{PL}}<0.0001\right)$. As the magnitude in shift of $\lambda_{\mathrm{em}}$ from that of TAA-th-BTD is the same as for TAA-th-BTDth-TAA $\left(\Delta \lambda_{\mathrm{em}} \approx 28 \mathrm{~nm}, \sim 0.1 \mathrm{eV}\right)$, as is the magnitude of narrowing electrochemical gap between the TAA oxidation and BTD reduction relative to TAA-th-BTD $\left(\triangle \Delta \mathrm{G}_{\mathrm{ET}}{ }^{0}=0.09 \mathrm{eV}\right.$, Table S1), this emission is characterised as ${ }^{1} \mathrm{TAA}^{-+}$-th-BTD"-th-AQ in nature The extremely low $\varphi_{P L}$ is consistent with quenching of the TAA ${ }^{*+}$. th-BTD"-th-AQ excited state by rapid intramolecular ET to the ${ }^{1}$ TAA $^{++}$-th-BTD-th-AQ*- CS state (i. e. further ET from the primary $\left(A_{1}\right)$ to the secondary acceptor $\left.\left(A_{2}\right)\right)$, as demonstrated in the following.

Spectroelectrochemical data (recorded in $\mathrm{CH}_{2} \mathrm{Cl}_{2}$ ) and UV-Vis transient absorption (TA) spectra (recorded in toluene) of TAAth-BTD-th-AQ are presented and compared in Figure 2. The TA difference spectrum (black trace in Figure $2 \mathrm{c}$ ) exhibits bleaching below $450 \mathrm{~nm}$, as well as broad absorption features at 540 and in the $650-800 \mathrm{~nm}$ range, consistent with the spectroelectrochemical signatures obtained for $\mathrm{AQ}^{*-}$ (blue trace in Figure $2 \mathrm{~b}$ ) and TAA*+ (red trace in Figure 2a). The combined data in Figure 2 clearly indicate the formation of the TAA ${ }^{-+}$-th-BTD-th-AQ- $\left(D^{++}-A_{1}-A_{2}{ }^{--}\right)$ $\mathrm{CS}$ state. The TA signal (Figure $2 \mathrm{C}$ ) forms within the time resolution of the pump laser ( $\sim 10 \mathrm{~ns})$.

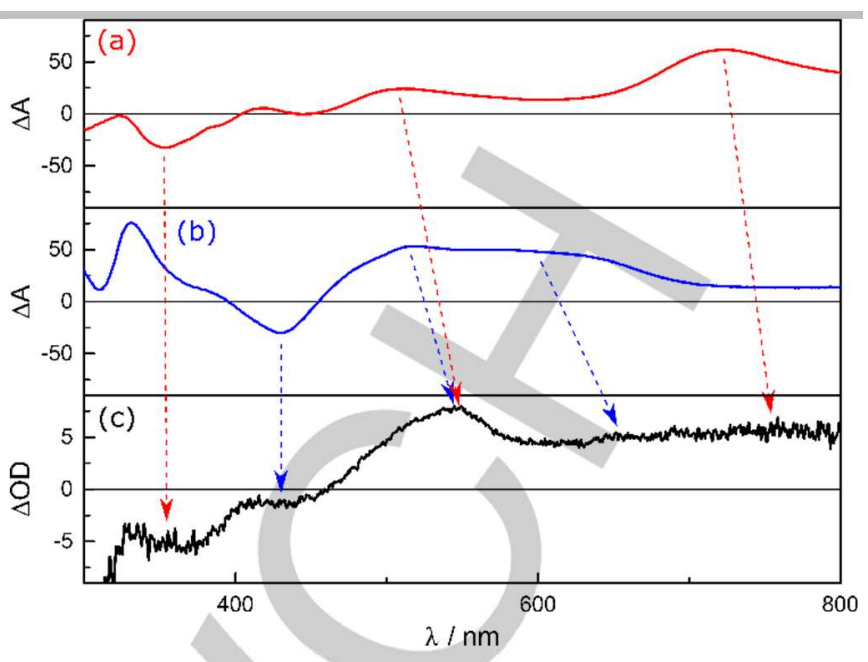

Figure 2. $\triangle \mathrm{A}$ spectra obtained upon electrochemical (a) TAA oxidation (red trace) and (b) $A Q$ reduction (blue trace) of TAA-th-BTD-th-AQ, recorded in $\mathrm{CH}_{2} \mathrm{Cl}_{2}$ in presence of $0.1 \mathrm{M} \mathrm{Bu}_{4} \mathrm{NPF}_{6}$, with applied potentials of 0.9 and $-1.1 \mathrm{~V}$ vs SCE, respectively, and (c) the transient absorption $\triangle O D$ spectrum of TAAth-BTD-th-AQ recorded in toluene at $298 \mathrm{~K}$ (black trace, $\lambda_{\mathrm{ex}}=410 \mathrm{~nm}$ ) immediately following excitation and time-integrated over $200 \mathrm{~ns}$.

Decay of the TA signal at $540 \mathrm{~nm}$ in de-aerated toluene at $298 \mathrm{~K}$ is biexponential, with lifetimes $(\tau)$ of $12.1(60 \%)$ and $31.9(40 \%)$ $\mu$ s (Table 1, Figure S11). The lifetimes of these states are quenched upon introduction of ${ }^{3} \mathrm{O}_{2}$, indicating that they are triplet in nature. As the rate of intersystem crossing (ISC) in organic molecules is slow compared to the rate of fluorescence, ET from $B T D *-$ to $A Q$ likely occurs within the singlet manifold. As back-ET from AQ*- to BTD is energetically disfavoured by $0.5 \mathrm{eV}$ (Table $\mathrm{S} 1)$, this state is thermodynamically trapped and slow ISC into the triplet manifold can occur. Alternatively, some reports have demonstrated that in strongly-coupled systems, direct electrontransfer from a singlet state to a triplet can occur through spinorbit coupling induced ET. ${ }^{[8]}$ Given that th bridges typically imbue strong electronic coupling, this represents a viable alternative mechanism for the formation of the ${ }^{3}$ TAA $^{-+}$-th-BTD-th-AQ* CS state.

Table 1. Lifetimes from decay of the transient absorption signal at $540 \mathrm{~nm}$ recorded as de-aerated $30 \mu \mathrm{M}$ solutions at $298 \mathrm{~K}\left(\lambda_{\mathrm{ex}}=410 \mathrm{~nm}\right)$.

$\begin{array}{ccc}\text { Solvent } & \tau_{1} / \mu \mathrm{s} & \tau_{2} / \mu \mathrm{s} \\ \text { Toluene } & 12.1(60 \%) & 31.9(40 \%) \\ 1,4 \text {-Dioxane } & 8.31(22 \%) & 53.9(78 \%) \\ \text { THF } & 7.76(17 \%) & 40.0(83 \%)\end{array}$

A molar extinction coefficient for the oxidised TAA of $17100 \mathrm{M}^{-1}$ $\mathrm{cm}^{-1}$ at $720 \mathrm{~nm}$ in $\mathrm{CH}_{2} \mathrm{Cl}_{2}$ was obtained from chemical oxidation experiments (Figure S9). Assuming minimal contribution from reduced $A Q$ at this wavelength, a quantum yield for the population of the ${ }^{3}$ TAA $^{*+}$-th-BTD-th-AQ*- $\left(\mathrm{D}^{*+}-\mathrm{A}_{1}-\mathrm{A}_{2}{ }^{-*}\right)$ CS state can be estimated as 0.07 ( $\mathrm{SI}$, page $\mathrm{S} 16)$ in toluene at $298 \mathrm{~K}$. A Jablonski diagram depicting the excited-state decay channels that lead to this low quantum yield is presented in Figure S14.

Upon changing solvent to 1,4-dioxane or THF, the signal decays become triexponential and do not return completely to baseline 
(Figure S11, left), consistent with the introduction of intermolecular quenching mechanisms. ${ }^{[9]}$ The lifetimes of the two shorter-lived components $\left(\tau_{1}\right.$ and $\left.\tau_{2}\right)$ are comparable to those in toluene, but the relative contribution of $\tau_{1}$ decreases and that of $\tau_{2}$ increases (Table 1). In principle, the two decay times $\tau_{1}$ and $\tau_{2}$ could reflect different ground-state conformers that undergo $C R$ with different kinetics. In order to clarify this point, TA measurements in a frozen 2-methyltetrahydrofuran (MeTHF) matrix at $77 \mathrm{~K}$ were insightful. The resulting TA decays are monoexponential (with a lifetime of $1.68 \mathrm{~ms}$; Figure S11, right), and since multiple different (frozen) ground-state conformers must be present under these conditions, it seems highly unlikely that different ground-state conformers would be responsible for the multiexponential decay behaviour observed in fluid solution at $298 \mathrm{~K}$. This strongly suggests that $\tau_{1}$ and $\tau_{2}$ are related to different ${ }^{3}$ TAA $^{-+}$-th-BTD-th-AQ*- CS state conformers dominated by significantly different $C R$ mechanisms. We hypothesised that conformational rearrangement in the CS state could lead to the formation of an ion-pair contact between between TAA ${ }^{*+}$ and $A Q^{*}$, facilitating through ion-pair $\mathrm{CR}^{[10]}$ akin to the previously reported 'harpooning' mechanism. ${ }^{[11]}$ Such ion-pairs exist in an equilibrium between a closed and open form, and as back-ET from AQ- to BDT is energetically disfavoured by $0.5 \mathrm{eV}$ (Table S1), the most likely mechanisms are tunnelling from $A Q^{-*}$ to $T A A^{\cdot+}$ through the covalent backbone of the triad (through-bond pathway), predominantly in the open form, and a through ion-pair pathway, predominantly in the closed form.

As direct experimental evidence for such a conformational change is very difficult to obtain, we turned first to TD-DFT calculations and then to temperature-dependent transient absorption studies (vide infra). B3LYP TD-DFT calculations predict the formation of a hydrogen-bond between a TAA ${ }^{\cdot+}$ proton and an $A Q^{*-}$ oxygen in both the $S_{1}$ and $T_{1}$ excited states, which correspond to the TAA ${ }^{-+}$-th-BTD-th-AQ*- CS state (Figure 3b), not present in the $S_{0}$ (ground) state (Figure $3 a$, Table S8). The calculated energy difference between the HOMO (TAA-based) and LUMO (AQ-based) models the difference in redox potentials of the TAA and $A Q$ within $10 \%$ error (Table S4), validating the calculation.

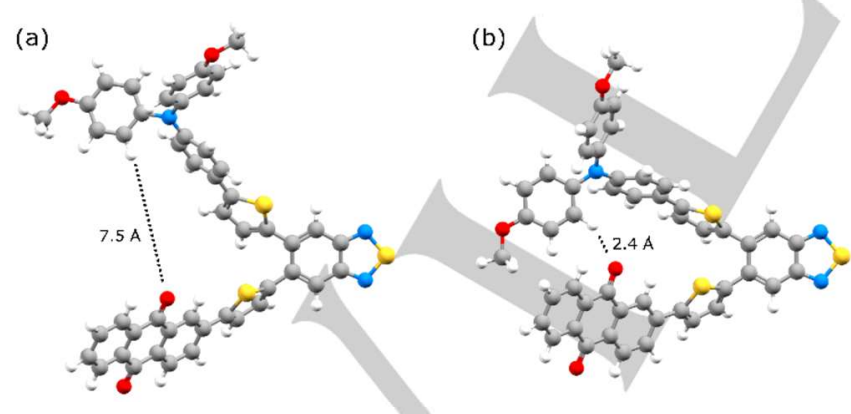

Figure 3. Geometry-optimised structures of TAA-th-BTD-th-AQ in (a) the ground state $\left(S_{0}\right)$ and; $(b)$ the lowest energy triplet excited state $\left(T_{1}\right)$, corresponding to the TAA ${ }^{-+}$-th-BTD-th-AQ*- $\left(D^{++}-A_{1}-A_{2}^{*-}\right)$ CS state, optimised at the B3LYP 6-31G(d,p) level of theory with a toluene SCRF solvent field.

As the solvent polarity is increased, the electron-hole pair in the CS state can be stabilised to a greater degree, shifting the equilibrium to a more open conformation (away from the ionpaired conformation). As such, the contribution of the ion-paired conformer to the excited-state decay should decrease with respect to that of the open form. The trends in $\tau_{1}$ and $\tau_{2}$ (Table 1) therefore suggest that $\tau_{1}$ is related to the ion-paired conformer (decreasing from $60 \%$ to $22 \%$ and $17 \%$ between toluene, dioxane and THF) and $\tau_{2}$ to the open conformer. Furthermore, due to the rigidity of the frozen matrix, ${ }^{[12]}$ the ground-state geometry (Figure $3 a$ ) is locked in, preventing conformational rearrangement and formation of an ion-pair contact in the frozen glass. The monoexponential decay at $77 \mathrm{~K}$ is therefore consistent with through-bond $\mathrm{CR}$. Due to large equilibrium torsion angles around the central BTD unit and long through-bond donor-acceptor distance in the CS state (Table S9), the long lifetime of $\tau_{2}$ is consistent with a through-bond mechanism. ${ }^{[9]}$ However, it is not possible to relate the solution decay times $\tau_{1}$ and $\tau_{2}$ directly to $C R$ rate constants of individual conformers, because the rate of interchange between open and closed conformations affects the observable time constants. In fact, the latter are expected to be a complicated combination of the various rate constants (see SI page S23). ${ }^{[13]}$ Therefore, the observed rate constants for the decay of the two conformers, $\mathrm{k}_{\mathrm{obs}-1}\left(\tau_{1}^{-1}\right)$ and $\mathrm{k}_{\mathrm{obs}-2}\left(\tau_{2}^{-1}\right)$, do not directly represent specific $C R$ mechanisms.

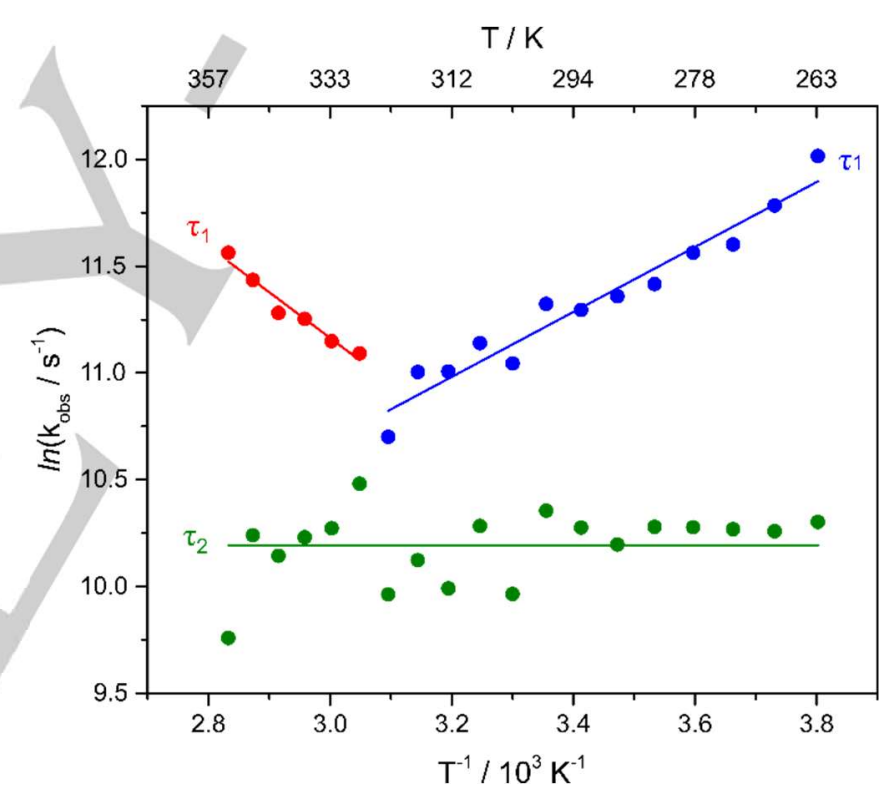

Figure 4. Arrhenius plots for TAA-th-BTD-th-AQ in toluene for $\tau_{1}$ (red and blue) and $\tau_{2}$ (green).

Nevertheless, variable temperature TA lifetime measurements in toluene (Figure 4) support our interpretation that $\tau_{1}$ is dominated by a through ion-pair CR pathway in the closed conformer. The temperature dependence of $\tau_{1}$ clearly exhibits two temperature regimes: a low temperature regime in which $\mathrm{k}_{\mathrm{obs}-1}$ decreases with increasing temperature (blue circles), and a high temperature regime in which $\mathrm{k}_{\mathrm{obs}-1}$ increases with increasing temperature (red circles). The lower temperature regime, which yields an apparent negative activation energy, is consistent with behaviour previously reported for intermolecular charge-transfer complexes. ${ }^{[14]}$ For example, Fukuzumi et al. demonstrated for hydride-transfer reactions that an apparent negative activation energy is only possible through the formation of a charge-transfer complex as a reaction intermediate. ${ }^{[14 a]}$ This is consistent with our 
hypothesis that $\tau_{1}$ is primarily related to the closed conformer and that the dominant $\mathrm{CR}$ pathway in this conformer is across the $\mathrm{TAA}^{*+} / \mathrm{AQ}^{*-}$ ion-pair contact. In this regime, increasing temperature shifts the equilibrium to a more open conformation (away from the ion-paired conformation), decreasing $k_{\text {obs- }-1}$ and leading to the apparent negative activation energy. $k_{\text {obs-2 }}$ exhibits no observable temperature-dependence (green circles), and this is not unprecedented for through-bond CR. ${ }^{[9]}$ Between 290 and $340 \mathrm{~K}$, the relative contribution of $\tau_{1}$ decreases with respect to $\tau_{2}$ (Figure S13), further consistent with thermal disruption of the ionpaired conformation. In the higher temperature regime, the relative contributions of $\tau_{1}$ and $\tau_{2}$ appear to plateau, and $\tau_{1}$ reflects ordinary behaviour with a positive activation energy (red circles in Figure 4). This is suggestive that increased thermal molecular motion leads to a greater number of spontaneous 'encounter complex' ion-paired conformers, in which CR occurs predominantly through the ion-pair contact or potentially through solvent-space. ${ }^{[15]}$

Thus, the combination of solvent- and temperature-dependent transient absorption studies with DFT calculations clearly points towards direct (forward) electron transfer from $\mathrm{AQ}^{*-}$ to $\mathrm{TAA}^{*+}$ across a short ion-pair contact, made possible as a result of the conformational flexibility of our $D-A_{1}-A_{2}$ triad. This process is in competition with ordinary through-bond $\mathrm{CR}$ as commonly observed in more rigid rod-like donor-bridge-acceptor constructs. Given an estimated quantum yield of 0.07 for formation of the TAA $^{++}$-th-BTD-th-AQ*- CS state in toluene at $298 \mathrm{~K}$ (SI, page S20), and a $60 \%$ contribution of $\mathrm{CR}$ from the ion-paired conformer at that temperature in toluene (Table 1, top left entry), a quantum efficiency for electrons travelling in a complete circuit can be estimated at 0.04 under these conditions.

In conclusion, we have herein communicated a donor-acceptoracceptor triad that provides the first proof-of-concept for a photoinitiated single-molecule circuit. The key design principles that have permitted such behaviour are: (i) excitation into an optical charge-transfer band to afford directly a primary chargeseparated state $\left(D^{++}-A_{1}{ }^{-}-A_{2}\right)$ with high efficiency (Scheme 1 , top right corner); (ii) rapid subsequent onward electron transfer to yield a very long-lived secondary charge-separated state $\left(D^{*+}-A_{1-}\right.$ $\mathrm{A}_{2}{ }^{-}$) (Scheme 1, bottom right); (iii) geometric reorganisation in this charge-separated state to form an ion-pair contact between $A_{2}{ }^{*}$ and $\mathrm{D}^{*+}$ (Scheme 1, bottom left).

We envisage that upon optimisation of the quantum efficiency of the photoinitiated molecular circuit, such systems may be expanded beyond a simple 'three-station' circuit to much more complex systems able to perform specific electronic functions and become incorporated as electronic devices. Furthermore, the controllable circular flow of electrons may have an associated magnetic field, enabling the development of a fundamentally new class of (photoswitchable) molecular magnets.

\section{Acknowledgements}

C. B. L. acknowledges a Swiss Government Excellence Postdoctoral Scholarship for Foreign Scholars. Financial support by the Swiss National Science Foundation through grant number 200021_146231/1 is gratefully acknowledged. The authors thank Dr. M. Kuss-Petermann and Dr. X. Guo for insightful discussion, and Dr. D. Häussinger for NMR support.
Keywords: electron transfer $\cdot$ donor-acceptor systems $\bullet$ timeresolved spectroscopy $\bullet$ charge transfer $\bullet$ ion pairs

[1] a) M. Kiguchi, Single-molecule Electronics, Springer, 2016; b) E. Scheer Molecular electronics: an introduction to theory and experiment, Vol. 1, World Scientific, 2010; c) F. Fassioli, D. G. Oblinsky, G. D. Scholes, Faraday Discuss. 2013, 163, 341-351.

[2] a) J. R. Heath, M. A. Ratner, Phys. Today 2003, 56, 43-49; b) L. Sun, Y. A. Diaz-Fernandez, T. A. Gschneidtner, F. Westerlund, S. Lara-Avila, K Moth-Poulsen, Chem. Soc. Rev. 2014, 43, 7378-7411; c) C. J. Lambert, Chem. Soc. Rev. 2015, 44, 875-888.

[3] a) M. Cordes, A. Kottgen, C. Jasper, O. Jacques, H. Boudebous, B. Giese, Angew. Chem. Int. Ed. 2008, 47, 3461-3463; b) V. A. Montes, C. Perez-Bolivar, N. Agarwal, J. Shinar, P. Anzenbacher, J. Am. Chem. Soc. 2006, 128, 12436-12438; c) M. T. Indelli, C. Chiorboli, L. Flamigni, L. De Cola, F. Scandola, Inorg. Chem. 2007, 46, 5630-5641; d) P. P. Edwards H. B. Gray, M. T. J. Lodge, R. J. P. Williams, Angew. Chem. Int. Ed. 2008, 47, 6758-6765; e) V. Lloveras, J. Vidal-Gancedo, T. M. Figueira-Duarte, J. F. Nierengarten, J. J. Novoa, F. Mota, N. Ventosa, C. Rovira, J Veciana, J. Am. Chem. Soc. 2011, 133, 5818-5833; f) A. C. Benniston, A. Harriman, Chem. Soc. Rev. 2006, 35, 169-179; g) C. Lambert, C. Risko, V. Coropceanu, J. Schelter, S. Amthor, N. E. Gruhn, J. C. Durivage, J. L. Brédas, J. Am. Chem. Soc. 2005, 127, 8508-8516; h) P J. Low, Dalton Trans. 2005, 2821-2824; i) U. Pfaff, A. Hildebrandt, D Schaarschmidt, T. Ruffer, P. J. Low, H. Lang, Organometallics 2013, 32, 6106-6117; j) D. C. O'Hanlon, B. W. Cohen, D. B. Moravec, R. F. Dallinger, M. D. Hopkins, J. Am. Chem. Soc. 2014, 136, 3127-3136; k) C. Olivier, S. Choua, P. Turek, D. Touchard, S. Rigaut, Chem. Commun. 2007, 3100-3102; I) B. Albinsson, M. P. Eng, K. Pettersson, M. U Winters, Phys. Chem. Chem. Phys. 2007, 9, 5847-5864; m) B. Albinsson, J. Mårtensson, J. Photochem. Photobiol., C 2008, 9, 138-155; n) W. B. Davis, W. A. Svec, M. A. Ratner, M. R. Wasielewski, Nature 1998, 396, 60-63; o) F. Giacalone, J. L. Segura, N. Martín, D. M. Guldi, J. Am. Chem. Soc. 2004, 126, 5340-5341; p) R. T. Hayes, M. R. Wasielewski, D. Gosztola, J. Am. Chem. Soc. 2000, 122, 5563-5567; q) K. E. Linton, M. A. Fox, L.-O. Pålsson, M. R. Bryce, Chem. Eur. J. 2015, 21, 3997-4007; r) A. B. Ricks, K. E. Brown, M. Wenninger, S. D. Karlen, Y. A. Berlin, D. T. Co, M. R. Wasielewski, J. Am. Chem. Soc. 2012, 134, 4581-4588; s) A. Arrigo, A. Santoro, F. Puntoriero, P. P. Lainé, S. Campagna, Coord. Chem. Rev. 2015, 304, 109-116; t) P. Jarosz, K. Lotito, J. Schneider, D. Kumaresan, R. Schmehl, R. Eisenberg, Inorg. Chem. 2009, 48, 24202428; u) C. D. Cruz, P. R. Christensen, E. L. Chronister, D. Casanova M. O. Wolf, C. J. Bardeen, J. Am. Chem. Soc. 2015, 137, 12552-12564 v) Y. Luo, K. Barthelmes, M. Wächtler, A. Winter, U. S. Schubert, B Dietzek, J. Phys. Chem. C 2017, 121, 9220-9229; w) M. Delor, T. Keane, P. A. Scattergood, I. V. Sazanovich, G. M. Greetham, M. Towrie, A. J. H. M. Meijer, J. A. Weinstein, Nat Chem 2015, 7, 689-695.

[4] a) J. Melomedov, J. R. Ochsmann, M. Meister, F. Laquai, K. Heinze, Eur. J. Inorg. Chem. 2014, 2014, 1984-2001; b) A. Magnuson, M. Anderlund, O. Johansson, P. Lindblad, R. Lomoth, T. Polivka, S. Ott, K. Stensjö, S Styring, V. Sundström, L. Hammarström, Acc. Chem. Res. 2009, 42, 1899-1909.

[5] a) M. Yamamoto, J. Föhlinger, J. Petersson, L. Hammarström, H. Imahori, Angew. Chem. Int. Ed. 2017, 56, 3329-3333; b) F. M. Toma, F Puntoriero, T. V. Pho, M. La Rosa, Y. S. Jun, B. J. T. de Villers, J. Pavlovich, G. D. Stucky, S. Campagna, F. Wudl, Angew. Chem. Int. Ed. 2015, 54, 6775-6779; c) D. Polyansky, D. Cabelli, J. T. Muckerman, E. Fujita, T. Koizumi, T. Fukushima, T. Wada, K. Tanaka, Angew. Chem. Int. Ed. 2007, 46, 4169-4172; d) J. H. Klein, T. L. Sunderland, C. Kaufmann, M. Holzapfel, A. Schmiedel, C. Lambert, Phys. Chem. Chem. Phys. 2013, 15, 16024-16030; e) K. Kitamoto, K. Sakai, Chem. Eur. J. 2016, 22, 12381-12390.

[6] a) O. Varnavski, P. Bäuerle, T. Goodson III, Opt. Lett. 2007, 32, 30833085; b) C.-K. Yong, P. Parkinson, D. V. Kondratuk, W.-H. Chen, A Stannard, A. Summerfield, J. K. Sprafke, M. C. O'Sullivan, P. H. Beton, H. L. Anderson, L. M. Herz, Chem. Sci. 2015, 6, 181-189.

[7] a) J. E. Barnsley, G. E. Shillito, C. B. Larsen, H. van der Salm, L. E. Wang, N. T. Lucas, K. C. Gordon, J. Phys. Chem. A 2016, 120, 1853-1866; b) 
C. B. Larsen, H. van der Salm, C. A. Clark, A. B. S. Elliott, M. G. Fraser, R. Horvath, N. T. Lucas, X.-Z. Sun, M. W. George, K. C. Gordon, Inorg Chem. 2014, 53, 1339-1354; c) C. B. Larsen, H. van der Salm, G. E. Shillito, N. T. Lucas, K. C. Gordon, Inorg. Chem. 2016, 55, 8446-8458 d) K. R. Justin Thomas, J. T. Lin, M. Velusamy, Y. T. Tao, C. H. Chuen, Adv. Funct. Mater. 2004, 14, 83-90.

[8] a) T. Higashino, T. Yamada, M. Yamamoto, A. Furube, N. V. Tkachenko, T. Miura, Y. Kobori, R. Jono, K. Yamashita, H. Imahori, Angew. Chem., Int. Ed. 2016, 55, 629-633; b) S.-H. Lee, A. G. Larsen, K. Ohkubo, Z.-L. Cai, J. R. Reimers, S. Fukuzumi, M. J. Crossley, Chem. Sci. 2012, 3, 257-269; c) M. R. Wasielewski, D. G. Johnson, W. A. Svec, K. M. Kersey, D. W. Minsek, J. Am. Chem. Soc. 1988, 110, 7219-7221.

[9] a) M. Kuss-Petermann, O. S. Wenger, J. Am. Chem. Soc. 2016, 138, 1349-1358; b) M. Kuss-Petermann, O. S. Wenger, Angew. Chem., Int Ed. 2016, 55, 815-819

[10] a) L. Troian-Gautier, E. E. Beauvilliers, W. B. Swords, G. J. Meyer, J. Am. Chem. Soc. 2016, 138, 16815-16826; b) M. Natali, F. Scandola, J. Phys. Chem. A 2016, 120, 1588-1600.

[11] a) T. Scherer, I. Van Stokkum, A. Brouwer, J. Verhoeven, J. Phys. Chem. 1994, 98, 10539-10549; b) W. Jäger, S. Schneider, J. Verhoeven, Chem. Phys. Lett. 1997, 270, 50-58.

[12] a) G. L. Gaines III, M. P. O'Neil, W. A. Svec, M. P. Niemczyk, M. R. Wasielewski, J. Am. Chem. Soc. 1991, 113, 719-721; b) P. F. Barbara T. J. Meyer, M. A. Ratner, J. Phys. Chem. 1996, 100, 13148-13168.

[13] a) S. I. Druzhinin, N. P. Ernsting, S. A. Kovalenko, L. P. Lustres, T. A. Senyushkina, K. A. Zachariasse, J. Phys. Chem. A 2006, 110, 2955 2969; b) S. I. Druzhinin, V. A. Galievsky, A. Demeter, S. A. Kovalenko T. Senyushkina, S. R. Dubbaka, P. Knochel, P. Mayer, C. Grosse, D. Stalke, K. A. Zachariasse, J. Phys. Chem. A 2015, 119, 11820-11836.

[14] a) S. Fukuzumi, K. Ohkubo, Y. Tokuda, T. Suenobu, J. Am. Chem. Soc. 2000, 122, 4286-4294; b) D. V. Matyushov, J. Phys. Chem. Lett. 2012, 3, 1644-1648; c) H. B. Kim, N. Kitamura, Y. Kawanishi, S. Tazuke, J. Am Chem. Soc. 1987, 109, 2506-2508.

[15] a) A. M. Napper, N. J. Head, A. M. Oliver, M. J. Shephard, M. N. PaddonRow, I. Read, D. H. Waldeck, J. Am. Chem. Soc. 2002, 124, $10171-$ 10181 ; b) A. M. Napper, I. Read, N. J. Head, A. M. Oliver, M. N. PaddonRow, J. Am. Chem. Soc. 2000, 122, 5220-5221; c) A. M. Napper, I. Read, R. Kaplan, M. B. Zimmt, D. H. Waldeck, J. Phys. Chem. A 2002, 106, 5288-5296; d) I. Read, A. Napper, R. Kaplan, M. B. Zimmt, D. H. Waldeck, J. Am. Chem. Soc. 1999, 121, 10976-10986. 


\section{Entry for the Table of Contents}

\section{COMMUNICATION}

We herein communicate a D-A-A triad that acts as a proof-of-concept for a photoinitiated molecular circuit, whereupon geometric rearrangement in a charge-separated excited state facilitates unidirectional electrontransfer around a complete circuit.

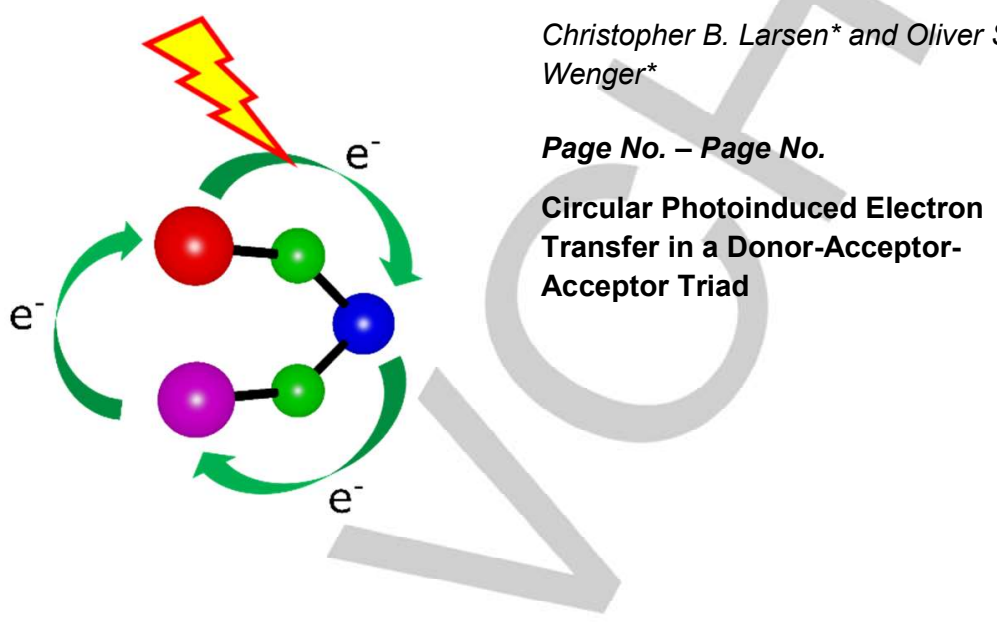

Christopher B. Larsen* and Oliver S.

Circular Photoinduced Electron Transfer in a Donor-Acceptor- 